\title{
MULTI-COMPONENT THEORIES OF WELL-BEING AND THEIR STRUCTURE
}

BY

ALEXANDER F. SARCH

\begin{abstract}
The 'adjustment strategy' currently seems to be the most common approach to incorporating objective elements into one's theory of well-being. These theories face a certain problem, however, which can be avoided by a different approach - namely, that employed by 'partially objective multicomponent theories.' Several such theories have recently been proposed, but the question of how to understand their mathematical structure has not been adequately addressed. I argue that the most mathematically simple of these multi-component theories fails, so I proceed to investigate more sophisticated ways to formulate such a theory. I conclude that one of these - the Discount/ Inflation Theory - is particularly promising.
\end{abstract}

It is becoming an increasingly common view among philosophers that well-being does not just depend on one's psychological responses, but rather, as David Brink puts it, also 'must contain important objective components. " What seems to motivate such views is the thought that while some sort of psychological responses (e.g. pleasures or desires) clearly are relevant to one's well-being, there are certain widespread intuitions that suggest that well-being cannot be determined solely by such responses. ${ }^{2}$ Thus any theory of well-being that is to adequately fit with our particular-case intuitions must allow certain kinds of responseindependent facts to affect well-being in one way or another. The correct theory, in other words, must be partially 'objective.'

If this is right (and let's suppose for the purposes of this article that it is), then we must address the question of how, exactly, it would be best to build the relevant response-independent, or 'objective,' elements into our theory of well-being. I argue that the most common sort of approach to this question - the adjustment strategy - suffers from a certain kind of

Pacific Philosophical Quarterly 93 (2012) 439-471 DOI: 10.1111/j.1468-0114.2012.01434.x

(C) 2012 The Author

Pacific Philosophical Quarterly (C) 2012 University of Southern California and Blackwell Publishing Ltd. 
defect, which leaves a different kind of approach - that represented by so-called multi-component theories - looking much more promising. However, while a number of theories of this latter sort have been proposed, insufficient attention has been paid to the question of how we should conceive of their mathematical structure. In this article, I aim to investigate this underexplored question.

The basic idea behind the adjustment strategy is fairly straightforward. First, one is to take one of the well-known subjective, single-component theories - like Hedonism or Desire Satisfactionism - according to which one's well-being is determined by the responses that one has towards the events that befall one (e.g. by how much pleasure one takes in things or by how much one desires what happens to one). The next step is to go on to claim that the degree to which a response of the relevant kind contributes to well-being is to be adjusted by certain objective facts (e.g. by how appropriate it is for one to be pleased by, or desire, the things that happen to one). Adams (1999), Darwall (2002), Feldman (2004), Kraut (1994) and Parfit (1984), to name just a few, all seem to propose theories of well-being that employ the adjustment strategy. However, as I will argue, these philosophers' theories all face problems of a certain sort. It does not seem that any of them can represent the whole truth about well-being.

These problems can be easily avoided, however, by theories that employ a different strategy for how to incorporate the relevant objective elements into one's theory. In particular, the problems facing the theories that employ the adjustment strategy can be avoided by certain multi-component theories of well-being. Very roughly, multi-component theories are the ones according to which there is more than one basic source of welfare value for a person (i.e. more than one fundamental good-making property whose instantiations directly and in themselves enhance well-being). ${ }^{3}$ Oldfashioned objective list theories, for instance, would count as multicomponent theories. However, here I will not be concerned with such theories insofar as they don't allow responses to count at all towards well-being. After all, entirely response-independent theories face wellknown problems. ${ }^{4}$ Instead, my focus will be the multi-component theories that are partially objective. These are the ones that make well-being depend on certain response-independent facts as well as certain psychological responses.

Several philosophers have recently suggested multi-component theories of just this sort. ${ }^{5}$ The trouble is that few of them have stated their theories in full detail. Most importantly, few of them discuss the question of precisely how the math for such a theory should be worked out. What mathematical operation should be performed on the various components of well-being in order to determine one's overall well-being? Addition? Something more complicated? There are many options, as we will see, and substantive investigation is required in order to decide which is best. Since 
partially objective multi-component theories can avoid the main problems faced by theories that employ the adjustment strategy, there is reason to be optimistic about the prospects of the former. Although this of course does not establish that the true theory of well-being must be a partially objective multi-component theory, it does provide motivation for looking more carefully at these theories and examining the various mathematical resources they make available for avoiding problem cases.

The order of business, then, will be as follows. First, I will discuss the recent single-component theories that employ the adjustment strategy. In particular, I will present the reasons for thinking that these theories are unable to capture the whole truth about well-being. The problems they face, while perhaps familiar, provide the motivation for looking more closely at multi-component theories. I then proceed to investigate the partially objective multi-component theories in more detail, paying special attention to the question of how it is best to conceive of their structure. The most mathematically simple version of this sort of theory has obvious problems, however, and so I go on to investigate some more sophisticated ways in which a multi-component theory might be constructed. I conclude that the second of these - the Discount/Inflation Theory - is particularly promising. Although I do not aim to give a full-blown defense of the view here, I do formulate it in some detail. For it represents a novel and, I think, attractive approach to pluralism in axiology that merits further investigation.

\section{The problem with adjustment theories}

The most common approach to formulating a theory of well-being that incorporates some objective element is to employ what I have called the adjustment strategy. A theory follows this strategy if it makes well-being depend on attitudes or psychological responses of some sort, but then maintains that exactly how good or bad it would be for one to have these attitudes or responses towards various things is to be adjusted by some factor that does not depend on one's responses. We may call a theory that fits this general pattern an objective adjustment theory.

\subsection{TWO TYPES OF OBJECTIVE ADJUSTMENT THEORY}

There are two main types of objective adjustment theory that have been suggested: those that apply the adjustment strategy to some kind of hedonist theory and those that apply it to some kind of desire satisfaction theory. Theories of the first type - which I will call the objectively adjusted enjoyment theories - take it that i) enjoyment of some kind enhances one's 
well-being, but ii) the degree to which a given episode of enjoyment contributes to well-being depends not just on the intensity and duration of that episode, but also on the degree to which the object of the enjoyment is worthy of being enjoyed. Thus on these theories, your life goes better for you the more you enjoy things of value.

Adams, Darwall, Feldman and arguably Parfit have proposed adjusted enjoyment theories of this sort. ${ }^{67}$ Adams defends the theory that, roughly speaking, a person's life contains well-being to the extent that it contains enjoyment of the excellent. As he puts it,

I shall argue that the principal thing that can be non-instrumentally good for a person is a life that is hers, and that two criteria (perhaps not the only criteria) for a life being a good one for a person are that she should enjoy it, and that what she enjoys should be, in some objective sense, excellent. Its being more excellent, and her enjoying it more, will both be reasons for thinking it better for her, other things being equal ... (Adams, 1999, pp. 93-94).

Darwall argues for the slightly different view that a person's life contains well-being to the extent that he that he appreciates things of value:

The normative claim I shall defend is that the best life for a person (in terms of welfare) is one involving activities that bring her into an appreciative rapport with various forms of agentneutral value, such as beauty, the worth of living things, and so on (Darwall, 2002, p. 17).

It seems reasonable to take it that 'being in appreciative rapport' with things of value, for Darwall, involves enjoying them, ${ }^{8}$ so Darwall's view, too, may be understood as an adjusted enjoyment theory. Feldman, too, outlines an adjusted enjoyment theory, namely Desert-Adjusted Intrinsic Attitudinal Hedonism (DAIAH). ${ }^{9}$ This is the theory, roughly, that you are well off to the extent that you take attitudinal pleasure ${ }^{10}$ in things that are more pleasure-worthy. Finally, Parfit, at least on one natural reading, also endorses an adjusted enjoyment theory:

What is good for someone is neither just what Hedonists claim, nor just what is claimed by Objective List Theorists. We might believe that if we have either of these, without the other, what we had would have little or no value. [. . .] On this view, each side in this disagreement saw only half the truth. Each put forward as sufficient something that was only necessary. Pleasure with many other kinds of object has no value. And, if they are entirely devoid of pleasure, there is no value in knowledge, rational activity, love, or the awareness of beauty. What is of value, or is good for someone, is to have both; to be engaged in these activities, and to be strongly wanting to be so engaged (Parfit, 1984, p. 502).

How, according to such a view, should the total amount of well-being contained in a person's life be calculated? Feldman's discussion of DAIAH suggests that the calculation should go roughly like this. First, find all the episodes of enjoyment in the life of the person in question, P. 
For each episode, find its raw value by multiplying its intensity by its duration. Then find its adjusted value by multiplying its raw value by the degree to which the object of this episode of enjoyment is worthy of being enjoyed - however this is to be understood (e.g. as excellence, agent neutral value, desert, or what have you). Once this is done, add up the adjusted values of all the episodes of enjoyment in order to get the total adjusted enjoyment contained in P's life. Then carry out analogous steps when it comes to the disenjoyment $\mathrm{P}$ experiences in order to find the total adjusted disenjoyment contained in P's life. Finally, subtract the adjusted disenjoyment in P's life from the adjusted enjoyment in P's life, and what you end up with is the total amount of well-being contained in P's life.

The second main kind of objective adjustment theories - which I will call the objectively adjusted desire satisfaction theories - hold that i) episodes of desire satisfaction are intrinsically good for one, while episodes of desire frustration are intrinsically bad for one, but ii) the degree to which such episodes are good or bad for one depends not just on the strength of the desire in question, but also on the objective value of the state of affairs that is desired. Thus on these theories your life goes better for you the more success you have in satisfying your desires for more worthwhile things.

This sort of theory, too, has recently received much discussion. Richard Kraut, for instance, seems to endorse a theory of this sort:

But if wanting something does not [by itself] make it good for the want to be satisfied, then we have to ask what does. My response is that what makes a desire good to satisfy is its being a desire for something that has features that make it worth wanting. Notice the difference between this approach and the one that lies behind the [traditional] desire theory. It says that we confer goodness on objects by wanting them; by contrast, my idea is that the objects we desire must prove themselves worthy of being wanted by having certain characteristics (Kraut 1994, p. 44).

And then he continues:

In order for our lives to go well our desires and emotions must be directed at objects whose features make them appropriate choices for us (Kraut 1994, p. 48).

T. M. Scanlon, ${ }^{11}$ too, could be read as expressing sympathy for some objectively adjusted form of Desire Satisfactionism:

I conclude that any plausible theory of well-being would have to recognize at least the following fixed points. First, certain experiential states (such as various forms of satisfaction and enjoyment) contribute to well-being, but well-being is not determined solely by the quality of experience. Second, well-being depends to a large extent on a person's degree of success in achieving his or her main ends in life, provided that these are worth pursuing (Scanlon 1998, pp. 124-125). 
This idea - that in general it is better for you to get your desires for more worthwhile things satisfied - has been discussed by others as well. ${ }^{12}$

Fully spelled out, an objectively adjusted desire satisfaction theory would recommend something like the following procedure for calculating the well-being contained in a person's life. First, find all the episodes of desire satisfaction in the life of the person in question, P. For each satisfied desire, find its raw value by multiplying the amount of time during which the desire in question is held by the average strength of that desire during that time. ${ }^{13}$ Then find its worthiness-adjusted value by multiplying its raw value by the degree to which the object of this desire is objectively valuable - however this is to be understood (e.g. as excellence, agent neutral value, desire-worthiness, or what have you). Once this is done, add up the worthiness-adjusted values of all the desire satisfactions in order to get the total worthiness-adjusted desire satisfaction contained in P's life. Then carry out analogous steps when it comes to the desire frustrations contained in P's life. This yields the total worthiness-adjusted desire frustration contained in P's life. Finally, subtract the worthiness-adjusted desire frustration in P's life from the worthiness-adjusted desire satisfaction in P's life, and what you end up with is the total amount of well-being contained in P's life.

\subsection{PROBLEMS WITH THE OBJECTIVE ADJUSTMENT THEORIES}

These two sorts of theory - the objectively adjusted enjoyment theories and the objectively adjusted desire satisfaction theories - seem to be the two main types of theory currently on offer that employ what I've called the adjustment strategy. However, each faces some problems that, while perhaps familiar, are nonetheless serious. Begin with the objectively adjusted enjoyment theories. The problem that these theories face is that they all imply that a life that contains no enjoyment (of the relevant sort) is entirely worthless for the one who leads it. ${ }^{14}$ This is simply a result of the way that these theories do the math. On these theories, episodes of enjoyment and disenjoyment are the only things that can bear value or disvalue. So even if a life contains a great deal of personal achievement or excellence or remarkable experiences, if it contains no episodes of enjoyment or disenjoyment, there are simply no value-bearing items in that life. No matter what the content of the life, the fact that there is no enjoyment or disenjoyment in the life leaves no possible way for value to be generated according to the adjusted enjoyment theories. Thus no matter what the content of a life might be, if it happens to contain no episodes of enjoyment or disenjoyment, then these theories will imply that this life has no welfare value whatsoever. Such a life, in other words, would be of no benefit to the one whose life it is. 
This implication seems implausible, however. Certain lives might be at least somewhat desirable even though they do not contain any enjoyment whatsoever. Consider the life of a highly active and successful person who, by some genetic fluke, is incapable of experiencing enjoyment or disenjoyment of any kind. Although his existence is cold and robotic, he is nonetheless highly active. He has some highly worthwhile goals and they guide his actions. What's more, because of his inability to feel pleasure or pain, he has no fear and no distractions, and this allows him to be singularly successful in pursuit of these goals. Such an existence, it seems to me, is by no means a worthless one. It would surely be preferable to not being alive at all. This, however, is inconsistent with what the adjusted enjoyment theories imply.

A related problem is that adjusted enjoyment theories have the implausible consequence that all of the lives that contain no enjoyment and no disenjoyment contain exactly the same amount of welfare value. This consequence does not seem plausible either. Of the lives containing no enjoyment or disenjoyment, some clearly seem to be better for one than others. For instance, a life of no enjoyment or disenjoyment that is spent exclusively watching paint dry would seem to be much worse for the one whose life it is than a singularly successful life that contains a range of remarkable experiences and achievements, but that also happens to contain no enjoyment or disenjoyment. In general, it is implausible to think that the welfare value of a life containing no enjoyment but lots of achievement is exactly the same as the welfare value of a life containing no enjoyment and no achievement either.

The opposite sort of problem undermines the objectively adjusted desire satisfaction theories. In particular, they are problematic because they fail to recognize the impact on well-being that enjoyment and disenjoyment (or happiness and unhappiness) seem to have. Consider a person - call him Bill - who leads a rather pleasant life, but who also happens to have exactly zero success in getting his desires for worthwhile things satisfied. Bill is as apathetic as anyone can be. He does not aim to accomplish anything and he has no projects to speak of. (He doesn't even care about having fun or being happy.) Most of the time, Bill merely sits around. It's not the case that he desires to just sit around all day, but it's also not the case that he desires not to sit around all day. Rather, he just doesn't care much either way. And this is how Bill feels about everything in life: utterly indifferent. Therefore, the amount of success that Bill has in getting his desires satisfied is zero. (Those who doubt that someone can have no projects or desires can just make the following assumption about the case: if there are any desires that Bill does have, then every satisfied one is exactly matched by a frustrated one of precisely the same intensity, duration and worthiness. Thus Bill's life really would contain zero desire satisfaction.) However, there is also an oddity about Bill. He has a birth 
defect that mysteriously causes him to take pleasure in mundane activities. When he walks across the room he feels a pleasant tingle in the soles of his feet. When he turns on the faucet, he finds the sound oddly enjoyable. $\mathrm{He}$ gets a little bit of a kick out of the yellow-ish tinge on the walls of his living room. And so on. Thus Bill's life actually contains a fair amount of pleasure. Nonetheless, Bill does not desire this pleasure. He does not seek it out, nor does he try to get more of it. It would not bother him in the least if the effects of his birth defect were cancelled, and all these little things pleased him no longer.

What would the objectively adjusted desire satisfaction theories imply about the life of Bill? They would imply that his is a worthless life. After all, Bill has no success whatsoever with respect to desires or goals. (He does not even succeed at satisfying his desire to be happy, since he has no such desire.) This implication seems counter-intuitive, however. For Bill actually experiences a reasonable amount of pleasure, even though he does not desire this or aim at it. Intuitively, Bill's life does seem to contain at least some positive amount of well-being. The objectively adjusted desire satisfaction theories cannot yield this result, however, because the amount of desire satisfaction that Bill's life contains is zero. These theories thus seem implausible because they cannot capture the intuition that some lives that contain no desire satisfaction can still contain a positive amount of well-being (e.g. if these lives are particularly pleasant ones). ${ }^{15}$

\subsection{THE LESSON TO DRAW FROM THESE PROBLEMS}

The upshot is that the two main types of theory that employ the adjustment strategy suffer from deficiencies. The objectively adjusted enjoyment theories seem to be problematic because they imply that any life (no matter how successful) that contains no pleasure or pain must contain no wellbeing. But there seems to be something other than enjoyment that can in itself enhance well-being, namely the accomplishment of one's worthwhile goals. By contrast, the objectively adjusted desire satisfaction theories seem to suffer from the opposite deficiency. They are problematic because they imply that any life (no matter how pleasant) in which the level of net adjusted desire satisfaction is zero must be a life that contains zero wellbeing. But there seems to be something other than the satisfaction of one's worthwhile desires that can in itself enhance well-being, namely happiness or enjoyment. Thus the one type of theory fails to take into account what the other type of theory recognizes as relevant to well-being, and vice versa.

An obvious way out of this set of problems would be to take one theory of each type and combine them so as to form a multi-component theory. In particular, what seems to be called for is a two-component theory that allows both one's enjoyment and one's success in satisfying worthwhile 
desires to make independent contributions to one's well-being. I will call multi-component theories of this sort enjoyment and achievement theories. By allowing both enjoyment and achievement to make independent contributions to one's well-being, such theories would be able to avoid the implausible implications of the single-component theories just discussed.

\section{A simple enjoyment and achievement theory: the additive theory}

We have seen the motivation for the enjoyment and achievement theories. But how, precisely, is it best to formulate a theory of this sort? This is the question that I will be chiefly concerned with in the remainder of this article. Some of the issues that one must take a stand on in order to fully state a theory of this type will not concern me much here. For one thing, there are major questions about how the concepts of enjoyment and achievement, which the theory is to be stated in terms of, should be understood. Moreover, there are major questions about exactly what objective factor we should think the welfare value of an episode of enjoyment or an episode of desire satisfaction is to be adjusted by. Is it desert? Excellence? Something else entirely? These are difficult questions and I have nothing new to say about them here. Instead, my focus will be the question of what relation we should think holds between the two components of well-being, according to such a theory. In other words, what is the mathematical structure that an enjoyment and achievement theory should be taken to have?

Given that this is going to be my focus here, I will make the following assumptions for the sake of clarity and simplicity. First, I will understand the theory's enjoyment-component along the lines of Feldman's DesertAdjusted Intrinsic Attitudinal Hedonism (DAIAH), since this is the most sophisticated account of what it means to 'enjoy things of value' that I am aware of. Thus when I from now on talk about the amount of 'enjoyment' contained in a person's life, what I mean is the amount of desert-adjusted intrinsic attitudinal pleasure contained in that life (as this is to be calculated according to DAIAH). ${ }^{16}$ Second, I will understand the achievementcomponent of well-being along the lines of objectively adjusted desire satisfactionism (OADS), as explained in the previous section. Thus when I talk in this article about the amount of 'objective achievement' contained in a person's life, what I mean is the net worthiness-adjusted desire satisfaction in that person's life. What's more, I should note that I do not have a fully worked out account of what makes the object of one desire more worthwhile than the object of another desire, or of what makes one thing more pleasure-worthy than another. However, I assume that some suitable account of these notions can be given. ${ }^{17}$ 
Given these assumptions, then, the simplest way to formulate an enjoyment and achievement theory would be to take it that your well-being simply is equal to the sum of the enjoyment in your life and the objective achievement in your life. ${ }^{18}$ Thus we would get the following additive theory of welfare:

\section{The Additive Theory:}

The amount welfare value contained in P's life equals the sum of:

a) the net desert-adjusted attitudinal pleasure in P's life (where this is to be calculated in the way DAIAH specifies), and

b) the net amount of worthiness-adjusted desire satisfaction in P's life (where this is to be calculated in the way that OADS specifies).

As an enjoyment and achievement theory, the Additive Theory has some appealing features. In particular, it avoids the problems that DAIAH and OADS were each seen to face by themselves. DAIAH by itself was problematic because it was impossible for a life devoid of enjoyment to contain a positive amount of welfare value. But according to the Additive Theory, this would indeed be possible, viz. if the life in question contained some objective achievement. The converse problem was seen to threaten a theory like OADS by itself. In particular, according to this theory, it was impossible for a life devoid of objective achievement to contain a positive amount of welfare. However, the Additive Theory implies that this would indeed be possible, viz. if the life in question contained some enjoyment. Thus the Additive Theory has some strengths that DAIAH and OADS by themselves lack.

Nonetheless, I will argue that the Additive Theory has some unattractive features. But before getting to that, let me respond to a preliminary objection. The Additive Theory relies on the perhaps controversial assumption that the units in which enjoyment is measured are commensurable with the units in which achievement is measured. That is, the theory assumes that it is in principle possible to determine what one unit of enjoyment is worth in terms of welfare compared to one unit of objective achievement. Some might have trouble accepting this assumption. However, I do not find this to provide sufficient reason to reject the theory. After all, there seems to be a natural way to determine the answer to this question (though I will not actually answer it myself here). Just as a hedonistic utilitarian might attempt to fix the relative (moral) value of pleasure and pain by requiring that a rational person would be indifferent between a) receiving exactly one unit of pleasure and one unit of pain, and b) receiving no pleasure and no pain, one might think that a similar approach can be taken when it comes to fixing the relative welfare value of enjoyment and achievement. In particular, we can take it that the following relation should hold between one unit of enjoyment and one unit of 
achievement: a rational person would be indifferent between a) a scenario in which she receives exactly one (additional) unit of enjoyment and no (additional) units of achievement, and b) a scenario in which she receives exactly one (additional) unit of achievement and no (additional) units of enjoyment. It does not matter precisely what the sizes of these units are, as long as one unit of the former corresponds to the amount that it would be rational to be indifferent about exchanging for a unit of the latter. Moreover, we can assume that we should go about determining exactly how much this is by employing the very same method that we use to answer other substantive evaluative questions: viz. the method of Reflective Equilibrium. It would be a long and hard process to actually answer this question, to be sure, but I see no reason to think it can't in principle be done. It is no harder than answering other substantive evaluative questions, and we are not in general pessimistic about finding answers to those. Thus I do not think that worries about the commensurability of enjoyment and objective achievement provide sufficient reason to reject the Additive Theory.

Nonetheless, I think that the Additive Theory faces two serious problems that $d o$ warrant the rejection of the theory. To see the first problem, consider what this theory implies about a life that contains an arbitrarily large amount of objective achievement, but that contains no enjoyment whatsoever. Is this a life high in welfare for the one who leads it? The Additive Theory would imply that it is. After all, the person in question here has been fantastically successful in accomplishing worthwhile goals. However, this consequence of the Additive Theory seems implausible. The life in question is not pleasurable in the slightest. It is not directly displeasurable either, but since it contains no feelings of enjoyment for the one who leads it, the life seems cold and detached. Although I think we should take it that this life contains some small positive amount of welfare, it would be counter-intuitive to say that this is a remarkably good life for the one who lives it. The life is missing something that is important, and it would seem strange if we could fully make up for a total lack of enjoyment just by adding more and more objective achievement. After all, things do not work this way, for example, when it comes to physical fitness. We do not think that a person who has no endurance, agility or speed whatsoever could be made arbitrarily physically fit just by being given, say, stronger and stronger biceps. Similarly, it would seem implausible if a life containing no enjoyment whatsoever could become arbitrarily high in welfare value just in virtue of having enough objective achievement. Because the Additive Theory has this implication, I think it is in trouble.

The Additive Theory faces the opposite problem as well. Consider a person who takes an astronomically large amount of pleasure in things that are pleasure-worthy almost (though not quite) to degree zero, but who has no objective achievement at all. For instance, suppose Jerry gets an arbitrarily large amount of pleasure from reading Trash Magazine, 
which (let us stipulate) is an activity with almost no pleasure-worthiness at all. Moreover, he experiences no pain or unhappiness. Finally, suppose that Jerry receives a score of exactly zero when it comes to objective achievement. (For every satisfied desire of Jerry's, we might say, there is a corresponding frustrated desire of equal strength, duration and worthiness.) How high, then, is Jerry's life in terms of welfare? The Additive Theory implies that Jerry's life contains an astronomically high amount of welfare. After all, it contains an arbitrarily large amount of pleasure. Indeed, the Additive Theory implies that there is in principle no limit on how well the life of a person like Jerry could be in terms of welfare. ${ }^{19}$

These consequences seem implausible, however. If there were a person who has no objective achievement to speak of, it would seem odd if this person's life could be made infinitely good in terms of welfare just by causing him to experience more and more low-quality pleasure. One might think that the mere addition of more and more pleasure cannot completely make up for utterly failing to accomplish anything worthwhile in life. If we do not accept that building stronger and stronger biceps can make one count as infinitely physically fit when one has no endurance, speed or agility, why should we think that this is the way it works when it comes to welfare? It is an intuitive thought that in order to have an exceptionally good life, a person must rank at least somewhat highly on all the scales that are relevant to welfare. This intuition, however, is one that the Additive Theory cannot accommodate. ${ }^{20}$

Both of these problems for the Additive Theory are the result of the way in which the theory does the math. In particular, the problems stem from the fact that the Additive Theory takes the amount of welfare in one's life to be simply the sum of the desert-adjusted enjoyment and the objective achievement it contains. Thus both problems can be avoided by versions of the enjoyment and achievement theory that do the math in a more sophisticated way than the Additive Theory.

\section{The thresholds theory}

If we want to construct an enjoyment and achievement theory that avoids the problematic implications of the Additive Theory without losing any of the theory's advantages, here is one natural way to do it: formulate a theory that incorporates thresholds in such a way that there is a certain minimum amount of well-being (greater than zero) that it is impossible to attain unless one has both a certain minimum amount of enjoyment and a certain minimum amount of objective achievement. In a moment, I will present this theory in detail - I will call it the Thresholds Theory. But as we will see, it also faces insurmountable problems. In the final section of this article, then, I will present another enjoyment and achievement theory - 
which I call the Discount/Inflation Theory - that avoids the main problems of the other theories discussed here.

\subsection{FORMULATING THE THRESHOLDS THEORY}

The Thresholds Theory begins with the assumption that there is some (positive) amount of well-being that you must reach in order to count as having a minimally good life. Any life containing less well-being than this is not a minimally good one. Moreover, the theory assumes that in order to reach the minimally good life point, you must have both a certain minimum amount of enjoyment and a certain minimum amount of objective achievement. ${ }^{21}$ Accordingly, if you have less than the minimum required amount of enjoyment, then no matter how much objective achievement you have, you will not have a minimally good life. More enjoyment will get you closer and closer to the minimally good life point, but it can never get your welfare score above that point. Similarly, if you don't have a certain minimum amount of objective achievement, then no matter how much enjoyment you experience, you also will not count as having a minimally good life. Again, more and more achievement will get you closer to the minimally good life point, but it will never get your welfare above that point. Thus, in order for you to have a life that is minimally good, your life must contain both the required minimum amount of enjoyment and the required minimum amount of achievement of worthwhile goals. Finally, when your enjoyment and your achievement are either both above threshold, or both below threshold, then your welfare just equals the sum of your enjoyment and your achievement. (Notice that to ensure the proper behavior, the minimally good life point must be set to equal the sum of the minimum enjoyment threshold and the minimum achievement threshold.)

Let's be a bit more precise. There are infinitely many ways in which we might formulate a welfare function that displays the behavior just described. Nonetheless, we can say, at a minimum, that the Thresholds Theory must be consistent with certain constraints. To state them, let ' $e$ ' stand for the amount of net enjoyment contained in P's life, as calculated by DAIAH, ' $a$ ' stand for the amount of achievement (i.e. success with respect to worthwhile projects) in P's life, as calculated by OADS, and ' $w$ ' stand for the amount of welfare contained in one's life. The conditions that the welfare function in a Thresholds Theory must satisfy, then, are these:

1) If either $e$ or $a$ is below threshold, then $w$ is below the minimally good life point.

2) If both $e$ and $a$ are equal to or above threshold, then $w$ equals the sum of $e$ and $a$. 
3) If both $e$ and $a$ are below threshold, then $w$ equals the sum of $e$ and $a$.

4) If $e$ is below threshold, then increasing $a$ will cause $w$ to approach the minimally good life point, but $w$ will never reach that point.

5) If $a$ is below threshold, then increasing $e$ will cause $w$ to approach the minimally good life point, but $w$ will never reach that point.

These conditions ensure that the Thresholds Theory avoids the problems that cast doubt on mathematically simpler theories like the Additive Theory. For one thing, the Thresholds Theory does not have the problematic implication that a person who has a tremendously large amount of success in accomplishing worthwhile goals, but who experiences little or no enjoyment, could have an arbitrarily good life. This is ensured by condition 1). Since the life of this person does not reach the minimum enjoyment level, this person's life will not count as a minimally good one. Similarly, the Thresholds Theory does not have problematic implications about people, like Jerry, who have virtually no objective achievement, but who experience vast amounts of (perhaps very low-quality) pleasure. The Additive Theory implied that such a person could have an arbitrarily good life even though he had no objective achievement. Again, the Thresholds Theory does not have this problematic implication, thanks to condition 1). If a life does not meet the minimum threshold for objective achievement, then the life cannot be a minimally good one - no matter how much additional enjoyment the person in question might receive.

\subsection{OBJECTIONS TO THE THRESHOLDS THEORY}

The Thresholds Theory thus avoids the two main problems of the Additive Theory. However, I do not think the Thresholds Theory should be endorsed. There is a preliminary objection to the theory that I think can in principle be answered, but it faces another more serious objection that I think is insurmountable.

Begin with the preliminary objection. A glaring challenge that the Thresholds Theory must deal with is the question of where to set the thresholds that it appeals to. The minimally good life point is fairly easy to deal with. I have just been assuming that it equals the sum of the enjoyment threshold and the achievement threshold. But this is not much progress. It just means that the real question is where to set the enjoyment threshold and the achievement threshold. This question is difficult, but I think not unanswerable. It is a substantive evaluative question, and so we must appeal to the same methods that we use to answer other such questions, namely the method of Reflective Equilibrium. In particular, we need to find values for the enjoyment threshold and the achievement threshold such that, when plugged into the Thresholds Theory, it gives intuitively 
plausible results - results that we find ourselves able to accept. I do not have room to take any meaningful steps towards determining where these thresholds should be set, but I see no reason to think that it cannot in principle be done.

Nonetheless, I think the Thresholds Theory should be rejected because the welfare-function that it employs displays bizarre behavior under certain circumstances. In particular, when you are above threshold on one scale but just below threshold on the other scale, then it will be possible for very small increases on the latter scale - increases just large enough to get you over threshold on that scale - to lead to dramatic increases in your welfare. Consider an example. Suppose you are very high above threshold with respect to enjoyment, but just under threshold with respect to objective achievement. Now suppose we add just a tiny bit of achievement to your life - that is, just enough to get you to reach the achievement threshold. According to the Thresholds Theory, this will cause a huge jump in your overall welfare. From being just below the minimally good life point, your welfare will now jump to a point far above the minimally good life point. This seems strange and arbitrary, however. In fact, this feature of the behavior displayed by the Thresholds Theory's welfare-function is so counter-intuitive that the theory should in my view simply be rejected.

\section{The discountlinflation theory}

In this section, I present one last version of the enjoyment and achievement theory. It has the same advantages as the Thresholds Theory, without displaying the strange mathematical behavior just discussed. Thus the theory presented in this section seems to avoid the main problems of the other theories discussed in this article. This theory, I think, represents a particularly promising approach to pluralism in axiology. ${ }^{22}$ (It should be clear that the approach suggested by this theory can be generalized to theories on which welfare contains more than two basic components. Working out the details, though, would be a complicated task.)

\subsection{AN INFORMAL ACCOUNT OF THE THEORY}

On the Discount/Inflation Theory, the degree to which your enjoyment contributes to your welfare - i.e. the magnitude of the enjoymentcontribution - is determined in part by the amount of objective achievement you have. On the other hand, the degree to which your objective achievement contributes to your welfare - i.e. the magnitude of the achievement-contribution - is determined in part by the amount of enjoyment you receive in life. The amount of welfare value in your life, then, simply equals the enjoyment-contribution plus the achievement- 
contribution. But to fully understand the Discount/Inflation Theory, we need to know exactly how the sizes of the enjoyment-contribution and the achievement-contribution are to be determined.

Let's focus on the enjoyment-contribution first. (The achievement contribution is to be understood in an analogous way.) The size of the enjoyment-contribution to your welfare is determined not only by the net amount of enjoyment in your life (i.e. the net amount of desert-adjusted intrinsic attitudinal pleasure you get), but also by how far above or below a certain threshold your level of objective achievement is. The threshold on the achievement scale is located somewhere above the zero point, but to see how the theory works it is not necessary to know exactly where. ${ }^{23}$ Now, when your net enjoyment is positive, there are going to be three cases (and there will be three corresponding cases for when your net enjoyment is negative). In particular, when your net enjoyment is positive, we need to know what happens to the enjoyment-contribution 1) when your achievement is below threshold, 2) when your achievement is above threshold, and 3 ) when your achievement is at threshold.

Begin with the first case. If your achievement score is below threshold, then the welfare value of the enjoyment you have in life gets progressively discounted. That is, for a given achievement level that is below threshold, increasing your net enjoyment gives you progressively less benefit in terms of welfare. And as your achievement level is decreased further and further below threshold, then the welfare value of your enjoyment gets discounted more severely. But no matter how low your level of achievement is, it will never be the case that more enjoyment will give you zero benefit in terms of welfare. More enjoyment is always better; it is just that when your achievement is below threshold, more enjoyment does less and less for you. A simple diagram (Figure 1) will help illustrate this:

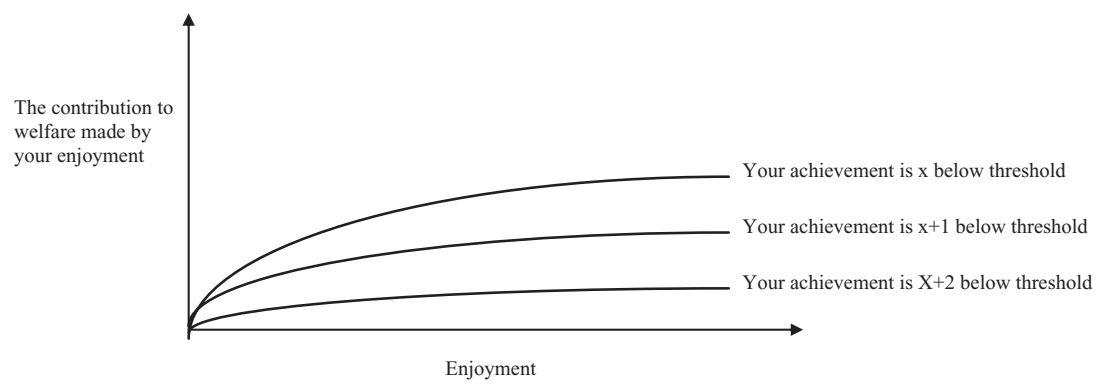

Figure 1 Case 1: Achievement below threshold; welfare value of the enjoyment in life is discounted.

Thus when we plot the welfare value contributed by the enjoyment contained in your life, then as we increase the amount of net enjoyment in 
your life, the derivative of the curve approaches zero. What's more, the further below threshold your achievement is, the lower the asymptote will be that the curve approaches (though the asymptote can never be a horizontal line at zero). This is what happens when your achievement level is below threshold. (This informal explanation leaves some questions unanswered, but the behavior in Case 1 can be captured precisely using mathematical notation. For ease of exposition, I relegate the technically precise formulation to an endnote. ${ }^{24}$ Endnotes $24-31$, read in succession, give a precise formulation of the theory.)

Now for the second case. If your achievement score is above threshold, then the welfare value of the net enjoyment you have in your life gets progressively inflated. That is, for a given achievement level that is above threshold, increasing your net enjoyment gives you progressively more benefit in terms of welfare. And as your achievement level is increased further and further above threshold, then the welfare value of your enjoyment gets inflated more dramatically. In other words, as your achievement level is increased above threshold, the amount of welfare you get for each additional unit of net enjoyment gets larger and larger. Again, a diagram (Figure 2) will help illustrate:

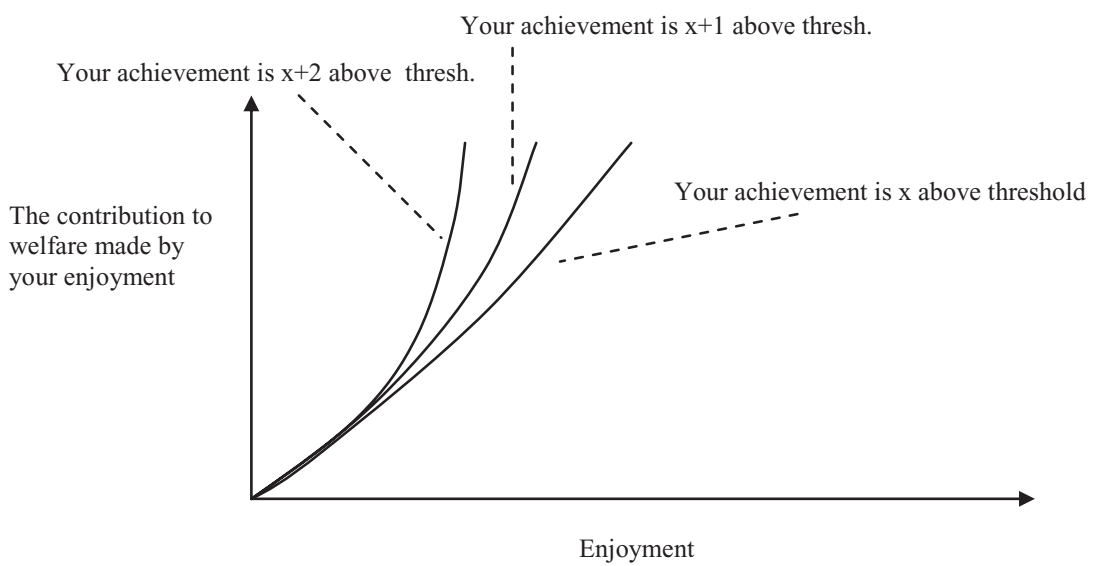

Figure 2 Case 2: Achievement above threshold; welfare value of the enjoyment in life is inflated.

So when your achievement level is above threshold, then as we increase the amount of net enjoyment in your life, the derivative of the curve increases. Increasing your achievement makes the derivative of the curve rise more quickly. (There are reasons to think that there must be some kind of upper limit on the inflation effect, however. Just as, in Case 1, decreasing achievement below threshold makes the asymptote that the curve approaches get 
closer and closer to zero, so too should we think that there is some upper bound that will be approached, in the case of inflation, as achievement is increased above threshold. For a precise account of the behavior in Case 2 , see the adjoining endnote. ${ }^{25}$ )

Finally, the third case. If your achievement is exactly at threshold, then the contribution to your welfare made by your enjoyment gets neither discounted nor inflated. In other words, no matter how much net enjoyment you have in life, you get the same amount of welfare for each additional unit of net enjoyment. A diagram (Figure 3) to represent this:

The contribution to welfare made by your enjoyment

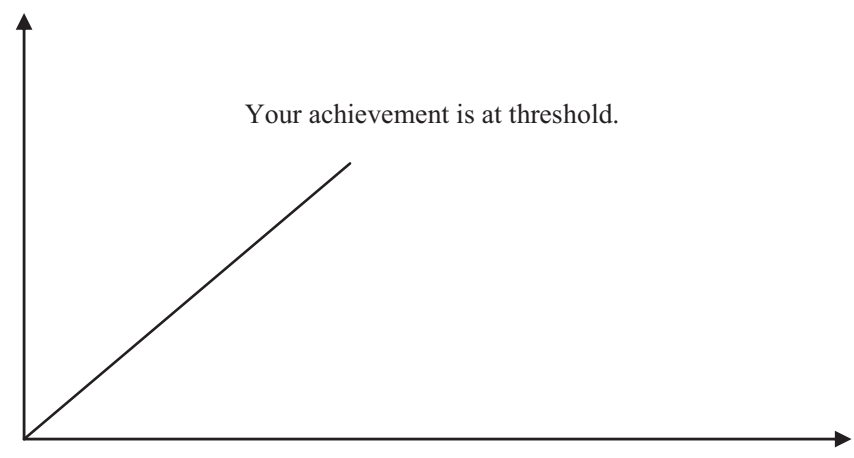

Enjoyment

Figure 3 Case 3: Achievement at threshold; welfare value of the enjoyment in life is neither discounted nor inflated.

So when your achievement level is at threshold, then as we increase the amount of net enjoyment in your life, the derivative stays the same. (See the endnote for a precise statement of the behavior in this case. ${ }^{26}$ )

These are the three cases that we encounter when the amount of net enjoyment you have in life is positive, i.e. when you have more happiness in life than unhappiness. But how do things work when your net enjoyment is negative, i.e. when you have more unhappiness in life than happiness? Again we encounter three cases.

To begin with, what happens when your net enjoyment is negative and your achievement is below threshold? The thought, in general, is that when your achievement level is below threshold, this has an adverse effect on the contribution made by enjoyment to your welfare. So when your net enjoyment is negative and your achievement is below threshold, the result is that as your net enjoyment is decreased (approaches minus infinity), you get hurt progressively more in terms of welfare. In other words, when your achievement is below threshold, more disenjoyment in your life will 
detract progressively greater amounts from your welfare. Visually represented (Figure 4):

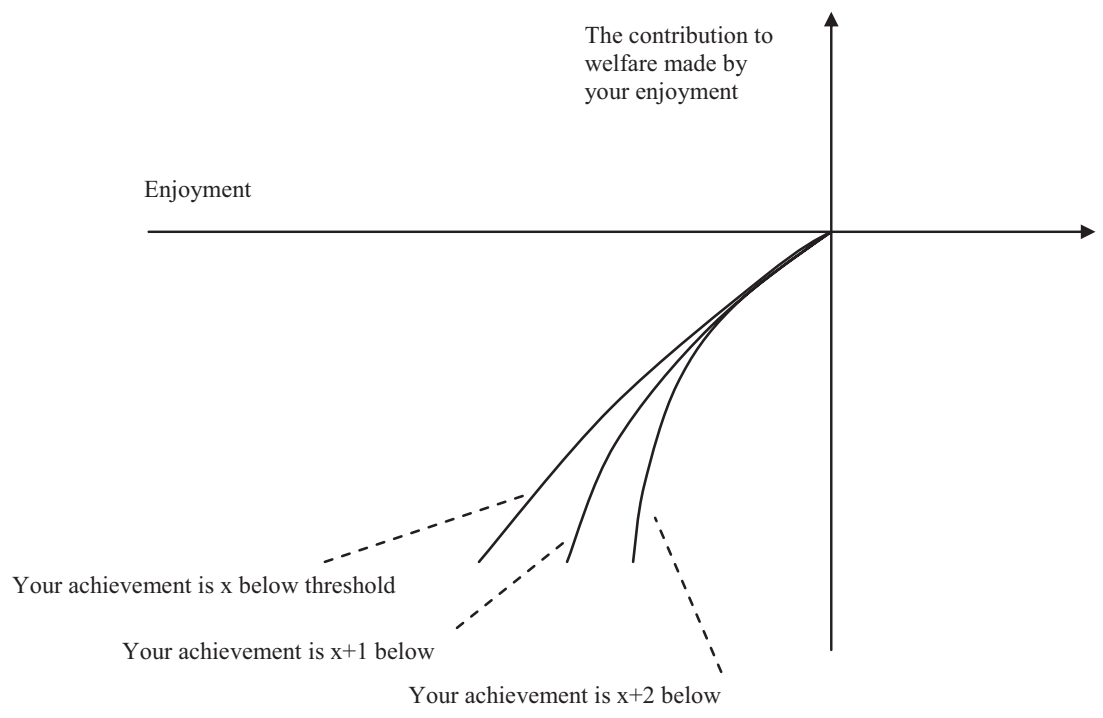

Figure 4 Case 4: Achievement below threshold; net enjoyment in life is negative.

So when your achievement level is below threshold, then as we decrease the amount of net enjoyment in your life further and further below the zero point, the derivative of the curve decreases as well. (As before, see the adjoining endnote for a precise account of the behavior in Case $4 .{ }^{27}$ )

Next, what happens when your net enjoyment is negative and your achievement is above threshold? The thought, in general, is that things go better for you when your achievement level is above threshold. So when your achievement is above threshold, it has a beneficial, mitigating effect on the contribution of your net disenjoyment to your welfare. When your net enjoyment is negative and your achievement is above threshold, the result is that you get hurt progressively less in terms of welfare for each additional unit of net disenjoyment you rack up in life. When your achievement is above threshold, more net disenjoyment in your life detracts progressively smaller amounts from your welfare. But no matter how high your level of achievement is, it will never be the case that more net disenjoyment in life will cause you zero harm in terms of welfare. More disenjoyment is always worse for you in terms of welfare; it is just that when your success is above threshold, more disenjoyment hurts you less and less. Represented visually (Figure 5): 


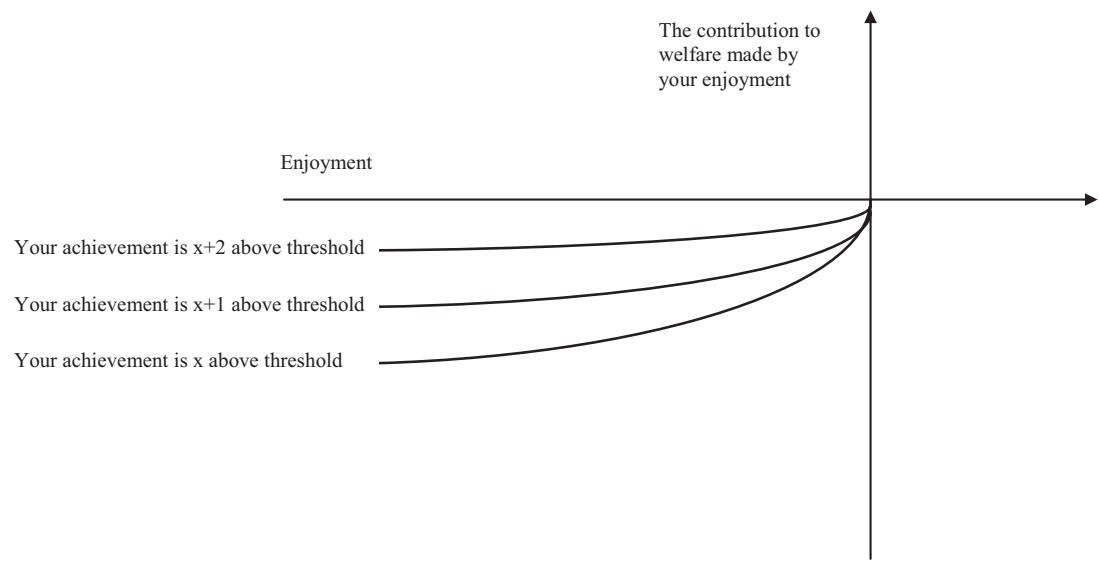

Figure 5 Case 5: Achievement is above threshold; net enjoyment in life is negative.

When your achievement level is above threshold, then as we decrease the amount of net enjoyment in your life further and further below the zero point, the derivative of the curve approaches zero. (See the endnote for a precise statement of this behavior ${ }^{28}$ )

Finally, what happens when your net enjoyment is negative and your achievement is at threshold? Just as before, the contribution to your welfare made by your net disenjoyment gets neither discounted nor inflated. In other words, you are clocked the same amount of welfare for each additional unit of net disenjoyment. Represented visually (Figure 6):

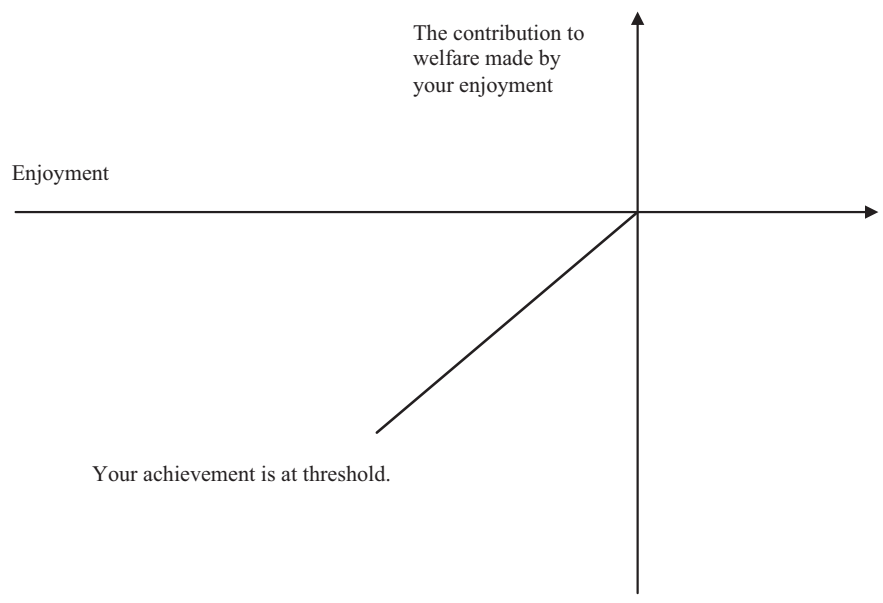

Figure 6 Case 6: Achievement at the threshold; net enjoyment is negative. 
As we increase the amount of net disenjoyment in your life, the derivative stays the same. This is what happens when your achievement level is at threshold. (The endnote provides a more precise account. ${ }^{29}$ )

Until this point, I have been sketching only how the size of the enjoyment-contribution to your welfare depends on achievement. But this is only half the story. We must also look at how the size of the achievement-contribution to welfare depends on enjoyment. This is straightforward, however, because things work in just the same way as they do for the enjoyment-contribution. Just as there is an achievementthreshold that is relevant for determining the size of the enjoymentcontribution to welfare, so too is there an enjoyment-threshold that is relevant for determining the size of the achievement-contribution to welfare. Again it is located somewhere above the zero point, though I will not attempt to say exactly where.

Now, just as with the enjoyment-contribution, we have a total of six cases here too: three for when your achievement is positive and three for when your achievement is negative. Case 7: When your achievement is positive and your net enjoyment is below threshold, the result is that you will get less and less welfare out of each additional unit of achievement in your life. That is, the welfare value of your achievement gets progressively discounted. Case 8: When your achievement is positive and your net enjoyment is above threshold, the result is that you will get more and more welfare out of each additional unit of achievement in your life. That is, the welfare value of your achievement will get progressively inflated. Case 9: When your achievement is positive and your net enjoyment is at threshold, the result is that for each additional unit of achievement, you will receive exactly the same amount of additional welfare. Case 10: When your achievement is negative, having a net enjoyment level that is below threshold will have an adverse effect. That is, you will get hurt progressively more in terms of welfare for each additional unit of net unsuccessfulness (failure) you rack up in life. Case 11: When your achievement is negative, having a net enjoyment level that is above threshold will have a mitigating effect. The result is that you will get hurt progressively less in terms of welfare for each additional unit of net unsuccessfulness (failure) you rack up in life. Case 12: When your achievement is negative, having a net enjoyment level that is at threshold has neither an adverse nor a mitigating effect. The result is that the degree to which you are hurt by additional units of net unsuccessfulness (failure) remains constant. No matter how much net unsuccessfulness (failure) you have in life, if your net enjoyment is at threshold, each unit of unsuccessfulness (failure) will hurt your welfare by the same amount. (As before, a precise account of the behavior of the achievement component of welfare is provided in the adjoining endnote..$^{30}$ )

Thus we see roughly how the size of the enjoyment contribution to welfare varies as a function of your achievement, and how the size of the 
achievement contribution to welfare varies as a function of your enjoyment. Thus we can state the theory as follows:

The Discount/Inflation Theory:

The amount of welfare contained in P's life equals the sum of i) the enjoyment contribution to P's welfare, as described in Cases 1)-6), and ii) the achievement contribution to P's welfare, as described in Cases 7)-12).

(See the endnote for a precise formal statement of the view. ${ }^{31}$ )

At this point it will be helpful to give an example of how the welfare value of a life as a whole is to be calculated, according to the Discount/ Inflation Theory. Consider again the case of Jerry. Recall that the Thresholds Theory had an advantage over the Additive Theory, in that the former can adequately accommodate intuitions about the case of Jerry, while the latter cannot. The Discount/Inflation Theory enjoys this same advantage over the Additive as well. Jerry's life is one that is unusually high in enjoyment, but contains no objective achievement. To keep things simple, suppose Jerry's level of achievement is just barely above the zero point. Thus his achievement is below threshold, while his net enjoyment is above threshold. What contribution do his enjoyment and his achievement make to his welfare? On the one hand, since his level of achievement is below threshold, the contribution to his welfare made by his enjoyment will get discounted to its small asymptotic limit (cf. Case 1). Thus, the large amount of enjoyment he receives will not provide much welfare for him. On the other hand, since his level of enjoyment is above threshold, the contribution to his welfare made by his achievement will be inflated (cf. Case 8). But Jerry has next to zero achievement in the first place. So this inflation effect remains minor. Accordingly, the tiny amount of achievement he has makes only a small positive contribution to his overall welfare. Now, to find the overall amount of welfare contained in Jerry's life, we must add up the enjoyment-contribution, which is small, and the achievement-contribution, which is also small. When we do this, the result is that Jerry's life contains only a small (or at best a mediocre) amount of welfare. And this, roughly speaking, is what I claimed is the intuitive result about the case of Jerry. Despite all his low-quality pleasure, it should be intuitive that Jerry does not have a fantastically good life in terms of welfare. And this is just the result that the Discount/Inflation Theory generates.

\subsection{ADVANTAGES OF THE DISCOUNT/INFLATION THEORY}

This rough presentation of the theory should be sufficient to show that the Discount/Inflation Theory avoids the problems that felled the other theories discussed in this article. For starters, the theory has at least as many 
advantages as the Thresholds version of the theory. As we just saw in discussing the case of Jerry, the Discount/Inflation Theory, like the Thresholds Theory, avoids the problematic implication that a person with a tiny amount of achievement can have an infinitely good life provided only that he gets enough enjoyment. For similar reasons, the Discount/ Inflation Theory, like the Thresholds Theory, also avoids the counterintuitive implication that a person with a tiny amount of enjoyment can have an infinitely good life provided only that he has enough achievement. For a person with little (below threshold) enjoyment and arbitrarily high achievement, the achievement contribution to welfare would be discounted to its small asymptotic limit (cf. Case 7), and the enjoyment contribution, although inflated, would still end up being be very small. Thus the life of such a person would contain only a small (or at best a mediocre) amount of welfare. So on the Discount/Inflation theory, to have an exceptionally good life in terms of welfare, one must have both a high amount of enjoyment (i.e. over threshold) and a high amount of objective achievement (i.e. over threshold).

What's more, the Discount/Inflation Theory is superior to the Thresholds Theory. Recall that the Thresholds Theory implied that sometimes very small increases with respect to one component of welfare could lead to bizarre jumps in overall welfare. For example, when you are high above threshold with respect to enjoyment, but just a tiny bit below threshold with respect to achievement, then adding just enough achievement to your life to get you to reach the threshold would cause a huge jump in your overall welfare, according to the Thresholds Theory.

This strange behavior does not arise on the Discount/Inflation Theory, however. After all, if your enjoyment is above threshold and your achievement is just below threshold, this will cause the enjoyment-contribution to your welfare to be discounted just a little bit, while the achievementcontribution to your welfare will get inflated. And adding just enough achievement to get you up to threshold will not cause a strange jump in your welfare. Instead, as your achievement level approaches threshold, the enjoyment-contribution to your welfare will smoothly cease to be discounted. As Case 1) shows, as your achievement approaches threshold from below, the discounting effect abates and the enjoyment contribution to welfare just becomes equal to the amount of net enjoyment contained in your life. Then, once your achievement goes slightly above threshold, the achievement contribution to your welfare will be equal to a number that is just slightly greater than the amount of net enjoyment in your life. This is because of the inflation behavior described by Case 2). Thus there are no jumps. The transition from the discounting effect in Case 1) to the inflation effect in Case 2) is seamless. Accordingly, the Discount/Inflation Theory will not allow small increases in either enjoyment or achievement to cause strange jumps in welfare. ${ }^{32}$ 
The Discount/Inflation Theory, therefore, seems to be clearly superior both to the Thresholds Theory and to the Additive Theory. I think it represents a particularly promising approach to formulating a multicomponent theory of well-being (though I do not claim to have given a full-blown defense of the view).

\subsection{AN OBJECTION CONCERNING INFLATION}

I want to end by briefly addressing an objection that might be raised when it comes to the inflation behavior that the theory provides for. ${ }^{33}$ Recall that on the Discount/Inflation Theory, the contribution to welfare made by, say, one's enjoyment gets inflated when one's achievement is above threshold. Accordingly, if a below-threshold achiever and an above-threshold achiever were to take the same amount of pleasure in precisely the same object, then this would benefit the high achiever's welfare more than it would the low achiever's. But one might wonder what the motivation for this inflation behavior is. Just because the one person is a high achiever, why should he get more welfare out of his pleasures than the low achiever would from qualitatively indistinguishable pleasures?

Several points can be raised in response. First, it is important not to over-estimate the force of the objection. When a high achiever and a low achiever take the same amount of pleasure in precisely the same object, then the pleasures would by their own lights provide the same benefit. This is, of course, still compatible with the episodes of pleasure differing with respect to the contributions they ultimately make to well-being. What's more, these two episodes occur in the context of different lives, and this could account for why they make different contributions to the overall desirability of those lives. After all, global features of a life might matter a great deal for how much welfare the various ingredients of that life provide (cf. Velleman, 1991).

More importantly, considerations of symmetry provide support for the inflation aspect of the theory. Inflation, after all, is the mirror image of discounting. That is to say, the behavior displayed in Case 1 (discounting) is the reverse of the behavior displayed in Case 2 (inflation), in just the way that Case 4 (discounting) and Case 5 (inflation) are mirror images of one another. (Moreover, there is also a sense in which Case 4 mirrors Case 2 and Case 5 mirrors Case 1.) These symmetry relations would be destroyed if discounting were allowed, but not inflation. A number of difficult questions would then arise about why the welfare contribution of, say, enjoyment would be linear (flat) when one is above the achievement threshold, but non-linear (curved) when below threshold. To avoid these awkward questions and preserve the symmetry of the theory, inflation as well as discounting must be incorporated. 
Still, one might not think that theoretical considerations of symmetry are enough to motivate the inflation behavior that is built into the theory. Are there also substantive considerations that provide intuitive support for this inflation behavior? I think so. In particular, one might think that lives containing both high achievement and high enjoyment are unusually rare, compared to lives with just one or the other. If so, the presence of both high achievement and high enjoyment in the same life might have a synergistic effect on the desirability of that life, due to the comparative rarity of lives with this combination of elements. By way of analogy, suppose strength by itself is fairly easy to come by and so is agility by itself, but the combination of strength and agility is particularly difficult to obtain. Accordingly, for someone who already possesses a lot of strength, there is greater difficulty involved in also obtaining a high level of agility. For the already strong person, attaining a significant degree of agility would be a more impressive feat than it would for someone who is not already strong to attain that same level of agility. Perhaps enjoyment and achievement are related in a similar way. In other words, perhaps enjoyment is harder to come by for very high achievers than for low or average achievers. Indeed, this seems quite plausible given the kinds of hard work and personal sacrifice (e.g. to comfort and leisure) that, in most pursuits, are required to achieve high levels of success. If this is right, then it would not be surprising if an extra unit of enjoyment turned out to be more welfare-enhancing for the high achiever than it would be for the low achiever. To the extent that these intuitions are plausible, we might want our theory of well-being to display inflation behavior as well as discounting.

So some answers to the current objection are available. However, if one doesn't share the sort of intuitions that would support the inflation aspect of the theory, then one might prefer a version of the theory that incorporates only discounting behavior (as in Cases 1 and 4) but no inflation behavior (as in Cases 2 and 5). I doubt that this would really result in a theory that is superior to the Discount/Inflation Theory presented above, but I cannot conclusively settle the issue here. What is most important for present purposes, after all, is just to appreciate how the mathematical resources made available by multi-component theories can be used to capture a variety of intuitions about well-being. More investigation ${ }^{34}$ will of course be needed to provide a full-blown defense of any particular multi-component theory.

\section{Conclusion}

In this article, I have taken some steps towards addressing the question of how it would be best to construct a theory of welfare that incorporates some kind of objective component(s). First, I argued that single- 
component theories - like DAIAH or OADS - that seek to incorporate objective factors in the manner of the adjustment strategy face serious problems. To avoid these problems, we saw that a multi-component theory of the enjoyment and achievement type seemed to be called for. However, the most mathematically simple enjoyment and achievement theory, namely the Additive Theory, was seen to face problems too. To avoid these problems, the enjoyment and achievement theory had to somehow make use of thresholds. However, I argued that the Thresholds Theory was not a promising way to do this. After all, it was seen to display bizarre behavior under certain circumstances. Instead, the most promising version of the enjoyment and achievement theory, I argued, was the Discount/Inflation Theory. This theory seemed particularly promising in light of its ability to avoid the main defects of the other theories discussed in this article. However, I have not attempted to provide anything like a complete defense of this view. Nonetheless, I think the Discount/Inflation Theory is deserving of further investigation. For if nothing else, the theory shows how the mathematical resources that are made available by multicomponent theories in axiology can be powerful tools for capturing new intuitions and avoiding old problems. ${ }^{35}$

\section{School of Law \\ University of Michigan}

\section{NOTES}

1 See Brink, 1989, p. 231. Similar views have been proposed by Robert Adams, 1999, pp. 93-94; Stephen Darwall, 2002, p. 17; Fred Feldman, 2004, p. 120; Richard Kraut, 1994; Derek Parfit, 1984, p. 502; and T. M. Scanlon, 1998, pp. 124-125. (Cf. Griffin, 1986, p. 33.)

2 The intuitions in question here are ones to the effect that there could be people who have exclusively positive attitudes or responses toward what happens to them, but who nonetheless do not seem to have particularly good lives. Many examples of this have been suggested. See, for instance, Feldman's case of Porky (2004, p. 40), which itself is based on a passage in G. E. Moore (1903, Section 56). Brink (1989, p. 227) offers the cases of Ludwig, who has immoral desires, and Zelda, who has trivial desires. In a similar vein, Kraut mentions the self-punisher (a person who desires his own misery) and the icicle-smashing fanatic. (Cf. Kraut, 1994, pp. 40-42.) Parfit and Rawls both discuss the person whose main ambition in life is to count the blades of grass in her front yard. (Cf. Parfit, 1984, p. 500 and Rawls, 1971, p. 432.) The conclusion that is typically drawn from such cases is that well-being must involve some sort of objective component or restriction. However, also note that there is much debate about what exactly these cases show and not everyone accepts a conclusion of this sort. (For some dissenters, see Heathwood, 2005 and Keller, 2004.)

3 The distinction between single component theories and multi-component theories is rather messy. After all, many theories involve several factors: Hedonism appeals to both pleasure and pain; Desire Satisfactionism appeals to satisfied and frustrated desires; theories that employ the adjustment strategy also make well-being depend on more than one factor. Still, I think these theories are reasonably classified as single-component theories, since they 
each take it that there is one basic source of intrinsic welfare value. Hedonism, for instance, claims that the one basic source of welfare value is pleasure, while a hedonistic adjustment theory would take it to be pleasure taken in worthwhile things. For present purposes, however, it will not be necessary to draw the distinction between single component and multicomponent theories in a precise way. After all, these labels are just a convenient way to refer to familiar groups of theories.

4 For some helpful discussions of the problems faced by objective list theories that fail to allow any sort of responses to count towards well-being, see Heathwood, 2006, p. 553; Kagan, 1998, p. 40; and Parfit, 1984, pp. 493-502.

5 See, for instance, Brink, 1989, p. 231-240; Scanlon, 1998, pp. 124-125; Keller, 2009; and Fletcher, manuscript.

${ }^{6}$ One might also take Mill to have defended this type of theory. However, Mill's actual view might be better classed as a subjective adjustment theory, not an objective one. (Here I am following Feldman, 2004, pp. 72-73.) There is reason to think that the welfare contribution of an episode of enjoyment has to be adjusted by its intrinsic features. For Mill, who didn't have the device of attitudinal pleasure available, it's likely that he would have to appeal to the pleasures' phenomenological properties in order to distinguish between the 'high' pleasures and the 'low.' But in that case, Mill's Hedonism would be a subjective adjustment theory. However, if one wants to reject this interpretation of Mill, then his view could also be classed as an objective adjustment theory. (In fact, Feldman [2004, p. 75] proposes a revision of Mill's view on which it would count as an objective adjustment view.)

7 I was recently made aware that a view of this sort is also defended in Kagan, 2009. While Kagan discusses some of the same mathematical devices that are built into the view I develop in the last section of this article (namely the Discount/Inflation Theory), Kagan's view is significantly different from the one I develop. See endnote 22 for more explanation of the differences.

8 Darwall himself recognizes the important connection between enjoyment and appreciating things of value. For instance, he says that 'pleasure is a sign of the activities' value, not its substance. What is pleasurable is, at least partly, the appreciation of merit and worth that these activities themselves involve. And what makes these pleasures loom so large in our welfare is the sense that, through them, we are connecting with things that matter' (Darwall, 2002 , p. 95). He then goes on to say that 'the primary source of prudential value is a felt appreciation of valuable activity, and not just belief or knowledge ...' (Darwall, 2002, p. 95).

9 See Feldman, 2004, p. 121.

${ }^{10}$ As Feldman explains this concept, 'A person takes attitudinal pleasure in some state of affairs if he enjoys it, is pleased about it, is glad that it is happening, is delighted by it' (Feldman, 2004, p. 56).

${ }^{11}$ Scanlon's views are complex, however, and in places he suggests that the notion of well-being is unhelpful and unnecessary for ethical theorizing. (See generally Scanlon, 1998, pp. 126-143.) However, this is not the place for extended Scanlon exegesis.

${ }^{12}$ Simon Keller, for instance, argues against a theory of this sort, which he calls The Restricted View: 'An individual's achieving her goals in itself contributes to her welfare, but only if the goals are of the right sort or are formed in the right way. Your achieving one of your goals contributes to your welfare just in case it's a goal that meets certain more or less restrictive conditions' (Keller, 2004, p. 28).

13 There are significant problems for desire satisfactionism when it comes to the question of how time is to be incorporated into the theory. But I cannot deal with them here. (For some good discussions, see Bykvist, 2006; Rabinowicz, 1989; and Hare, 1989.)

${ }^{14}$ Feldman points this out himself (at least with respect to Intrinsic Attitudinal Hedonism, or 'IAH'): 'No matter how much knowledge, virtue, honor, wealth, health, longevity, loving 
relationships, etc. he many have, if he takes pleasure in nothing, there is no basis for attributing positive intrinsic value to his life according to IAH. [. . . ] a life without attitudinal pleasure or pain is a life without value' (Feldman, 2004, p. 67).

${ }^{15}$ A related problem for the objectively adjusted desire satisfaction theories is this. They imply that if there were a person who experienced no happiness or unhappiness in life, but who had a tremendous amount of success in getting his desires for worthwhile things satisfied, then this person's life would be a fantastically good one for him. But this implication, too, seems counter-intuitive. How can a life be fantastically good if it contains no happiness whatsoever? Intuitively, a life must contain at least some happiness if it is to be one that is fantastically high in welfare value. More about this problem in the next section.

${ }^{16}$ For a full explanation of what this amounts to, see Feldman, 2004, pp. 120-123.

${ }^{17}$ Also note that while the discussion below concerns two-component theories of wellbeing, the considerations I raise are not limited to theories with only two components. If one prefers a theory on which well-being involves more than two components, what I say below can be easily extended to cover such a theory as well.

${ }^{18}$ Of course, this rests on the assumption that units of enjoyment and units of objective achievement are commensurable in such a way that the former can be added to the latter. I will defend this assumption in a moment.

${ }^{19}$ To see this, just imagine a string of cases involving Jerry-like people, where each person takes a progressively greater quantity of pleasure in the same nearly worthless objects (and where the amount of success in achieving worthwhile goals remains the same - i.e. zero or extremely close to it). Each life in this string of cases would be better in terms of welfare than the last. Since there is no principled limit to how much pleasure one of these lives can contain, there is no limit to how well the life of a Jerry-like person can go in terms of welfare according to the Additive Theory - even though he has a vanishingly small amount of objective achievement.

${ }^{20}$ Perhaps the present problem for the Additive Theory can be brought out more forcefully if the point is made in terms of a comparison of lives. Consider a person like Jerry who has virtually no success in accomplishing anything worthwhile, but who takes a fantastically large amount of pleasure in things that are pleasure-worthy to a low degree. Thus the total amount of desert-adjusted pleasure in his life would be a very large number $\mathrm{X}$ (make $\mathrm{X}$ as large as you want), while the total amount of success in his life is something close to 0 . Now compare Jerry's life with the more balanced life of Kerry. Kerry takes a moderately large amount of pleasure in exactly the same not-very pleasure-worthy things that Jerry enjoys. Thus suppose the total amount of desert-adjusted pleasure in Kerry's life is X/4. However, unlike Jerry, Kerry also has a moderately high degree of objective achievement. Suppose, in fact, that the amount of success in Kerry's life also happens to equal X/4. Now, whose life is better in terms of welfare value? The Additive Theory implies that Jerry's life is better than Kerry's. After all, according to this theory, Jerry has a huge amount of welfare, X, but Kerry's welfare is merely $\mathrm{X} / 2$. However, this result seems strange. It is by no means clear that Jerry's life is vastly better than Kerry's life. After all, there is something important missing from Jerry's life that Kerry's life contains, namely some kind of accomplishment or successful activity. Kerry's success might well more than compensate for the additional pleasure that Jerry has in his life. Since the Additive Theory generates results that are inconsistent with the intuitive understanding of this case, I find the theory to be problematic.

${ }^{21}$ In order to formulate the theory, we do not need to know exactly where these thresholds are to be set, only that there are some such cutoff points on the number line. More will be said about this question below. (Note, however, that the minimally good life point must equal the sum of the minimal enjoyment level and the minimal achievement level. Thus the main substantive question is where these latter two thresholds are to be set.) 
${ }^{22}$ As I mentioned before, it has recently been brought to my attention that Shelly Kagan (2009) discusses some of the same mathematical devices that the Discount/Inflation Theory employs. However, there are important differences between the view he sketches and the Discount/Inflation Theory formulated here. The Discount/Inflation Theory posits a complex relationship between two independently motivated components of welfare - namely achievement (as understood by OADS) and enjoyment (as understood by DAIAH). By contrast, what Kagan is concerned to investigate is the welfare contribution of particular episodes of pleasure taken in various objects. In particular, he thinks there is a complex function from i) the intensity of the pleasure and ii) the value or quality of its object to iii) the overall welfare contribution made by that episode of pleasure. Thus on his view, welfare consists in one thing, namely 'enjoyment of the good,' the value of which is calculated in a sophisticated way. By contrast, the Discount/Inflation Theory takes it that achievement and enjoyment make independent contributions to welfare, though the magnitude of that contribution depends on the other in complex ways, and vice versa. Thus while the Discount/Inflation Theory concerns the relationship between independently motivated components of well-being, Kagan's view amounts to a single-component theory of well-being that employs an unusually sophisticated version of adjustment strategy (which admittedly may allow it to avoid some of the problems for such theories raised in Section 1). Accordingly, they are related but importantly different theories.

${ }^{23}$ Again, I assume that the best level to pick for the achievement threshold can be determined by considering all the different possibilities, and then seeing which one would make the theory yield the most intuitively plausible results.

${ }^{24}$ The behavior in Case 1 can be captured precisely as follows. Let ' $W_{e}$ ' stand for the enjoyment contribution to welfare, ' $e$ ' stand for the amount of net enjoyment contained in your life, and ' $a$ ' stand for the amount of achievement contained in your life. In the graph for Case $1, W_{e}$ is plotted as a function of $e$, for fixed values of $a$. Now, notice that for fixed values of achievement $a$, the enjoyment-contribution, $W_{e}$, looks very much like a simple power of $e$. The power that $e$ is raised to varies as a function of $a$. Thus, we can say that:

$$
W_{e}=e^{f(a)}, \text { when } e \geq 0
$$

(Note: this equation will apply for Cases 2 and 3 as well.) We can ensure that this function will behave as described in Case 1 by imposing certain conditions on $f(a)$ in (1). In particular, when $e$ equals zero or is a positive number, then these conditions must be met:

(1.1) If $a$ is below threshold, then $f(a)<1$

(1.2) As $a$ decreases to minus infinity, $f(a)$ decreases and approaches 0

This captures the behavior of $W_{e}$ in Case 1, where $e$ is positive and $a$ is below threshold. Discounting is supposed to occur in this case. That is, $W_{e}$ is supposed to get discounted in such a way that for each additional unit of net enjoyment, you get less and less welfare in return. Condition (1.1) tells us that whenever $a$ is below threshold, the power to which $e$ is raised will be less than 1 . What this means is that when $a$ is below threshold (and $e$ is positive), $W_{e}$ will always be a number that is less than $e$. Moreover, because $e$ is being raised to a power less than 1 , for each unit by which the total amount of enjoyment in your life is increased, you get progressively less welfare from it. However, condition (1.2) tells us that it will never be the case that adding additional units of enjoyment affords you absolutely no welfare benefit whatsoever (or has a negative impact on your welfare). You will always get some additional welfare benefit from each added unit of net enjoyment. Thus conditions (1.1) and (1.2) together capture the way $W_{e}$ is supposed to behave in Case 1 . 
${ }^{25}$ Again, we can explain the required behavior more precisely by placing simple conditions on $f(a)$ in function (1), introduced earlier:

$$
W_{e}=e^{f(a)} \text {, when } e \geq 0
$$

The behavior in Case 2, where enjoyment, $e$, is positive and achievement, $a$, is above threshold, can be guaranteed by requiring that $f(a)$ satisfy two more conditions:

(1.3) If $a$ is above threshold, then $f(a)>1$

(1.4) As $a$ increases to infinity, $f(a)$ increases and approaches some constant (presumably 2)

These conditions produce the desired inflation effect. Condition (1.3) tells us that whenever $a$ is above threshold, the power to which $e$ is raised will be greater than 1 . What this means is that when $a$ is above threshold (and $e$ is positive), $W_{e}$ will always be a number that is greater than $e$. Moreover, because $e$ is being raised to a power greater than 1 , for each unit by which the total enjoyment in your life is increased, you get more and more welfare from it. However, it would seem there needs to be a limit on how quickly the enjoyment-contribution can be inflated. And this is what condition (1.4) ensures. In particular, it tells us that as $a$ increases to infinity, the power to which $e$ is raised will grow to approach 2. That is, as $a$ approaches infinity, the curve for $W_{e}$ will look more and more like the curve for $e^{2}$.

At this point, two questions arise: why do we need to impose any limit at all on how high $f(a)$ can get, and why should 2 be picked for this upper limit? Begin with the first question. If no upper limit were placed on the degree to which the enjoyment-contribution to your welfare could be inflated as your achievement level goes to infinity, then this would lead to counter-intuitive results. Recall the person who had a tremendous amount of achievement but very little enjoyment. The Additive Theory was seen to be problematic precisely because it implied that such a person could have an arbitrarily good life, provided only that he had enough achievement. A similar problem would threaten the Discount/ Inflation Theory if there were no top limit on how much one's enjoyment could be inflated, as $a$ is increased to infinity. For if there were no such top limit, then for a person who has a tiny (below threshold) positive amount of enjoyment but an arbitrarily large amount of achievement, $W_{e}$ would become arbitrarily high too. And in that case, the contribution to welfare made by this person's tiny amount of enjoyment would be arbitrarily high. But as I argued in Section 2, this seems counter-intuitive. Intuitively, you cannot have an arbitrarily good life if you have only a tiny amount of enjoyment - no matter how much achievement you have. To prevent this counter-intuitive result, we cannot allow that $f(a)$ can become arbitrarily high as $a$ is increased to infinity. Thus we need $f(a)$ to asymptotically approach some constant as $a$ gets bigger and bigger.

Next, why should this constant should be set at 2 in particular, as condition (1.4) suggests? Considerations of symmetry require that the constant be 2. Condition (1.2) implies that as $a$ is decreased from the threshold level to minus infinity, then $f(a)$ will begin at 1 and then asymptotically approach 0 . Thus $f(a)$ (i.e. the power to which $e$ is raised) can change by a maximum of 1 as $a$ is decreased from threshold to minus infinity. Accordingly, symmetry would suggest that same thing should happen when $a$ is increased above threshold. That is, $f(a)$ should be allowed to change by a maximum of 1 in the positive direction, as $a$ is increased from the threshold level to plus infinity. Thus we get condition (1.4), saying that as $a$ is increased from the threshold level to infinity, $f(a)$ (i.e. the power to which $e$ is raised) should begin at 1 and then asymptotically approach 2 . 
${ }^{26}$ The behavior in Case 3 can be captured by imposing one final condition on $f(a)$ in function (1), namely:

(1.5) If $a$ is at threshold, then $f(a)=1$

This guarantees that when $e$ is positive and $a$ is exactly at threshold, no inflation or discounting will occur. For in this case, condition (1.5) ensures that $f(a)$ (i.e. the power that $e$ is raised to) equals 1 . Thus when $a$ is exactly at threshold, $W_{e}$ will just be equal to $e$.

${ }^{27}$ To precisely capture the behavior of $W e$ (the enjoyment contribution to welfare) when $e$ (your net enjoyment) is negative, we need to introduce a new function to replace (1). For taking a negative number and raising it to a fractional exponent will be undefined in some cases. Thus to allow for fractional exponents when $e$ is negative (which will be needed in a moment for Case 5), what we are going to need is this:

$$
W_{e}=-\left(|e|^{f(a)}\right) \text {, when } e<0(\text { where }|e| \text { is the absolute value of } e) \text {. }
$$

Now we can capture the behavior of $W_{e}$ in Case 4 by imposing the following two conditions on $f(a)$ in (2):

(2.1) If $a$ is below threshold, then $f(a)>1$

(2.2) As $a$ decreases to minus infinity, $f(a)$ increases and approaches some constant (presumably 2)

These conditions produce the desired discount effect. Condition (2.1) tells us that whenever $a$ is below threshold and $e$ is negative, the power to which $|e|$ is raised will be greater than 1. What this means is that when $a$ is below threshold and $e$ is negative, $W_{e}$ will always be a number lower than $e$ (a negative number). This constitutes discounting. For each unit by which the total enjoyment in your life is decreased below zero, you get hurt progressively more in terms of welfare. However, as with Case 2, there needs to be a limit on how dramatically the enjoyment-contribution can be discounted. And this is what condition (2.2) ensures. In particular, it tells us that as $a$ decreases to minus infinity, the curve for $W_{e}$ will look more and more like the curve for $-|e|^{2}$.

${ }^{28}$ The behavior of $W_{e}$ in Case 5 can be captured by imposing the following two conditions on $f(a)$ in (2):

(2.3) If $a$ is above threshold, then $f(a)<1$

(2.4) As $a$ increases to infinity, $f(a)$ decreases and approaches 0

Condition (2.3) tells us that whenever $a$ is above threshold and $e$ is negative, $W_{e}$ will always be a number that is greater than $e$. Hence the mitigating effect. For each additional unit of net disenjoyment in your life, you get hurt progressively less in terms of welfare by it. Moreover, condition (2.4) tells us that decreasing your net enjoyment below zero will always hurt your welfare at least somewhat. Thus conditions (2.3) and (2.4) together capture the way $W_{e}$ is supposed to behave in Case 5.

${ }_{29}$ The behavior in Case 6 can be captured by imposing one final condition on $f(a)$ in function (2), namely:

(2.5) If $a$ is at threshold, then $f(a)=1$

This guarantees that when $e$ is negative and $a$ is exactly at threshold, no inflation or discounting will occur. For in this case, condition (2.5) ensures that $f(a)$ (i.e. the power 
that $|e|$ is raised to) equals 1 . Thus when $a$ is exactly at threshold, $W_{e}$ will just be equal to $e$.

${ }^{30}$ Since, the achievement-contribution to welfare - call it ' $W_{a}$ ' - behaves in the same way as the enjoyment-contribution to welfare, $W_{e}$, the behavior of $W_{a}$ can be captured in just the same way as was that of $W_{e}$. That is, just as conditions were imposed on $f(a)$ in (1) and (2), we must impose analogous conditions on $g(e)$ in the following two equations:

$$
W_{a}=a^{g(e)}, \text { when } a \geq 0
$$

$$
W_{a}=-\left(|a|^{g(e)}\right) \text {, when } a<0(\text { where }|a| \text { is the absolute value of } a)
$$

The desired behavior of $W_{a}$ can be generated by imposing one condition on $g(e)$ in (3) and (4) for each condition imposed on $f(a)$, in (1) and (2), in the preceding footnotes. It should be obvious how this would go, so it won't be necessary to state all ten conditions on $g(e)$ here.

31 The theory can also be stated more precisely: the total amount of welfare in one's life equals the sum of $\boldsymbol{W}_{e}$, as described by equations (1) and (2) together with the conditions placed on $f(a)$, viz. (1.1)-(1.5) and (2.1)-(2.5), and $\boldsymbol{W}_{\boldsymbol{a}}$, as described by equations (3) and (4) together with the analogous conditions to be placed on $g(e)$.

Elsewhere, I have formulated a concrete mathematical function that captures the behavior of $W_{e}$ and $W_{a}$ that was sketched in the discussion of Cases 1-12. See Appendix III to Sarch, 2009 (Thanks to John Arthur Skurd for his invaluable assistance here).

${ }^{32}$ More precisely, this is because, assuming $e$ is greater than 0 , conditions (1.1), (1.4) and (1.5) together make it the case that as $a$ approaches the achievement threshold from below, $f(a)$ will approach 1 , and so the value of $W_{e}$ will approach being equivalent to $e$. Then once $a$ goes slightly above threshold, $W_{e}$ will be equal to a number that is just slightly greater than $e$. This behavior is generated by conditions (1.3) and (1.4). Thus the Discount/Inflation Theory will not allow small increases in either enjoyment or achievement to cause strange jumps in welfare.

${ }^{33}$ Thanks to an anonymous reviewer for this journal, and to Pete Graham, for pressing me on this issue.

${ }^{34}$ An anonymous reviewer for this journal has raised another sort of worry about the inflation aspect of the Discount/Inflation theory. In particular, one might think that the inflation effect is a step in the direction of creating utility monsters. It might give us reason to try to give those who already are above the relevant thresholds more enjoyment and achievement than those who are below threshold, in order to maximize overall utility. Nonetheless, I think this is not really a problem for the Discount/Inflation Theory itself. After all, the problem arises only if one adopts certain simple utilitarian theories of right action, rather than some more sophisticated version of utilitarianism, or even a nonutilitarian theory. The problem would not come up, for example, on a desert-adjusted form of utilitarianism of the sort that Fred Feldman (1995) proposes. On this view, the right thing to do is not maximizing the total amount of well-being in the world, but rather maximizing the overall amount of [well-being as adjusted by the degree to which each person deserves the amount of well-being she receives]. The present concern, therefore, seems to be a worry only on certain theories of right action (i.e. simple forms of utilitarianism), and is not a problem for the Discount/Inflation Theory of well-being per se. We can sidestep the worry, it seems, just by adopting a more plausible theory of right action.

${ }^{35}$ First and foremost, I would like to thank John Arthur Skard for many extremely helpful conversations about how to formulate the multi-component theories developed in this article, 
as well as how to capture their behavior mathematically. I would also like to thank Fred Feldman, Guy Fletcher, Pete Graham, Hilary Kornblith and an anonymous reviewer for this journal for helpful comments on previous drafts.

\section{REFERENCES}

Adams, R. M. (1999). Finite and Infinite Goods: A Framework for Ethics. New York: Oxford University Press.

Brink, D. O. (1989). Moral Realism and the Foundations of Ethics. Cambridge: Cambridge University Press.

Bykvist, K. (2006). 'Prudence for Changing Selves,' Utilitas: A Journal of Utilitarian Studies 18(3), pp. 264-283.

Darwall, S. (2002). Welfare and Rational Care. Princeton, NJ: Princeton University Press.

Feldman, F. (1995). 'Adjusting Utility for Justice: A Consequentialist Reply to the Objection from Justice,' Philosophy and Phenomenological Research 55, pp. 567-585.

Feldman, F. (2004). Pleasure and the Good Life: Concerning the Nature, Varieties, and Plausibility of Hedonism. Oxford: Clarendon Press.

Fletcher, G. (manuscript). 'A Fresh Start for Objective-List Theories of Well-Being.'

Griffin, J. (1986). Well-being: Its Meaning, Measurement and Moral Significance. New York: Oxford University Press.

Hare, R. M. (1989). 'Prudence and Past Preferences; Reply to Wlodizimierz Rabinowicz,' Theoria: A Swedish Journal of Philosophy 55, pp. 152-158.

Heathwood, C. (2005). 'The Problem of Defective Desires,' Australasian Journal of Philosophy 83(4), pp. 487-504.

Heathwood, C. (2006). 'Desire Satisfactionism and Hedonism,' Philosophical Studies: An International Journal for Philosophy in the Analytic Tradition 128(3), pp. 539-563.

Kagan, S. (1998). Normative Ethics. Boulder, CO: Westview Press.

Kagan, S. (2009). 'Well-Being as Enjoying the Good,' Philosophical Perspectives 23(1), pp. 253-272.

Keller, S. (2004). 'Welfare and the Achievement of Goals,' Philosophical Studies: An International Journal for Philosophy in the Analytic Tradition 121, pp. 27-41.

Keller, S. 2009, 'Welfare as Success,' Noûs 43(4), pp. 656-683.

Kraut, R. H. (1994). 'Desire and the Human Good,' Proceedings and Addresses of the American Philosophical Association 68(2), pp. 39-54.

Moore, G. E. (1903). [1993] Principia Ethica. Cambridge University Press, $2^{\text {nd }}$ edn. New York: Cambridge University Press.

Parfit, D. (1984). 'What Makes a Person's Life Go Best?' in Reasons and Persons. New York: Oxford University Press, p. 493.

Rabinowicz, W. (1989). 'Hare on Prudence,' Theoria: A Swedish Journal of Philosophy 55, pp. $145-151$.

Rawls, J. (1971). A Theory of Justice: Revised Edition. Cambridge: Harvard University Press.

Sarch, A. F. (2009). 'On the Objectivity of Welfare,.' Dissertation, University of Massachusetts Amherst.

Scanlon, T. M. (1998). What We Owe to Each Other. Cambridge: Harvard University Press. Velleman, D. J. (1991). 'Well-Being and Time,' Pacific Philosophical Quarterly 72, pp. 48-77. 